Folia primatol 1974;22:329

\title{
Addenda and Corrigendum
}

My paper 'A New Genus of Late Oligocene Monkey (Cebidae, Platyrrhini) with Notes on

Postorbital Closure and Platyrrhine Evolution' (Folia primat. 21:1-35,1974), requires the following additions and correction.

Add Montaneia Ameghino 1910, the Cuban monkey indicated on the map (fig. 1, p. 2), to the classification (p. 27) under Ateles as a synonym (vide Miller, Smithson.misc. Coll. 16: No. 13, 1,1916).

Primate Incertae Sedis, known from the distal end of a tibia dug from kichen midden on Samaná Bay, Dominican Republic, Hispaniola (northeastern portion of large island SE of Cuba, map, fig. 1). The find was first described by Miller (Smithson. misc. Coll. 82: No. 5, 5, 1929) who thought it matched the tibia of Cercopithecus better than any comparably sized living American monkey. Williams and Koopman (Amer.Mus.Novit. 1546, 3,1952) indicated, however, that the fragment was pre-Columbian and therefore a New World primate not certainly identifiable with any living form. Add it as Incertae Sedis (Miller, 1929; Williams and Koopman, 1952), to the scheme on p. 27, following Branisella.

Figure 9, p. 16. Labels for Aotus reading 'ofis' and íofis, should read from above down, iofis and lofis. Evidently, the first letter of each term was cropped when the plate was locked for printing. P. Hershkovyrz 